\title{
Postoperative Wound Pain and Hospital Stay in Patients of Open Lumbar Discectomy (OLD) Versus Endoscopic Lumbar Discectomy (ELD) in Lumbar Disc Herniation (LDH)
}

\author{
SYED SHAHZAD HUSSAIN ${ }^{1}$, USMAN AHMAD KAMBOH ${ }^{1}$, ASIF RAZA ${ }^{1}$ \\ ADIL AMIN", SAMAN SHAHID ${ }^{2}$, NAVEED ASHRAF ${ }^{\mathbf{1}}$ \\ ${ }^{1}$ Department of Neurosurgery, Jinnah Hospital, Lahore Pakistan \\ ${ }^{2}$ Department of Sciences \& Humanities, National University of Computer \& Emerging Sciences \\ (NUCES), Foundation for Advancement of Science \& Technology (FAST), Lahore, Pakistan.
}

DOI: $10.36552 /$ pjns.v24i1.414

\begin{abstract}
Background: Endoscopic lumbar discectomy is also beneficial regarding relieving wound pain, less hospital stay and smaller incisions. We compared visual analog scores (VAS) and hospital stay in patients treated with either endoscopic lumbar discectomy or open lumbar discectomy postoperatively.
\end{abstract}

Material and Methods: Half patients underwent open lumbar discectomy - OLD (group A) and half operated with endoscopic lumbar discectomy - ELD (group B). The pain was quantified through visual analog score (VAS) observation in all patients. A preoperative medical management included prescribing a combination of an analgesic and a muscle relaxant along with physiotherapy with an avoidance of lifting heavy loads. MannWhitney $(U)$ tests were applied for the comparison of postoperative VAS and hospital stay between groups.

Results: $85 \%$ patients were having left sided prolapsed paracentral disc, and $15 \%$ were having right sided prolapsed paracentral disc. The mean postoperative VAS was 4 in patients treated with ELD and it was 1.32 in patients treated with OLD. The mean hospital stay was 1.5 days in ELD treatment, whereas, it was 2.5 days in OLD treatment. A significant difference $(p=0.037)$ was found in the comparison of mean post-operative VAS between two vertebral levels (i.e., L4-L5 \& L5-S1). The post-operative VAS and hospital stay (days) in ELD group were statistically significantly higher than the OLD group (p values 0.000).

Conclusion: ELD procedure was effective as compared to open lumbar discectomy in terms of postoperative wound site pain and hospital stay. Endoscopic Lumbar discectomy is a minimally invasive procedure for discectomy.

Keywords: Open Lumbar Discectomy (OLD); Endoscopic Lumbar Discectomy (ELD); Visual Analogue Score (VAS); Lumbar Disc Herniation (LDH); Left/Right Sided Prolapsed Paracentral Disc; L3-L4, L4-L5, L5-S1.

\section{INTRODUCTION}

Spine disorder from a degenerative disc is the main cause of disabilities in adult population worldwide. It was estimated that around 1.5 million disc surgeries are being performed every year around the globe. The incidence of sciatica is 5 in 1000 per year. ${ }^{1-2}$ Lumbar Date of Submission: 21-1-2020) is a more common source of Date of Printing: 31-3-2020 sciatica. More than $50 \%$ patients recover with nonsurgical therapies. ${ }^{3}$ Lumbar disc herniation (LDH) has been ranked $5^{\text {th }}$ among all diseases related to the frequent hospital admission, cost of the treatment and absent from the work. ${ }^{2}$ A survey of 2008 showed that almost $26 \%$ of the U.S. population had low backache. ${ }^{1}$ The current study was focused to compare mean pain 
scores and hospital stay in endoscopic lumbar discectomy (ELD) and open lumbar discectomy (OLD) treatmentsin patients with lumbar disc herniation (LDH) postoperatively. In lumbar spine complications, a lumbar disc herniationis a commonest pathology. Sciatica is a severe lower backache which radiates towards ipsilateral leg in the distribution of spinal nerve involved. Lumbar disc herniation is a significant cause of a lower backache. Lumbar disc herniation occurs due to the degeneration of the annulus fibrosis. Factors associated with lumbar disc herniation are age, improper working posture, bearing heavy loads, trauma and smoking, etc. ${ }^{5}$ Common age for lumbar disc herniation is $30-45$ years, with a male to female ratio of almost $3: 1{ }^{6}$ The Lumbar disc herniation is commonly occurs at either postero-lateral (para-central) or lateral, but sometimes posterior (central) herniation is also reported. Among the vertebral levels L4 - L5 and L5 - S1, the intervertebral disc is herniated in almost $95 \%$ patients with $22-50$ years of age. A level above L4 is relatively common in an older age. ${ }^{7-8}$ The clinical symptoms depend on the level of disc herniation as well as its direction. The symptoms include lumbago, sciatica, motor or sensory deficit along with the distribution of nerve root involved and claudication. ${ }^{9}$ MRI is a gold standard investigation for the diagnosis and treatment planning, ${ }^{10}$ which divides the herniated lumbar disc into four grades (I, II, III \& IV). The management of grades I \& II is conservative that includes analgesics, muscle relaxants, bed rest and physiotherapy. Grade III can also be managed conservatively in almost $85 \%$ of cases. ${ }^{11}$ A surgical intervention is indicated in case refractory to medical therapy, i.e., failure of medical therapy of six weeks or the progression of symptoms despite on medication in grades III \& IV. ${ }^{11}$

When a conservative therapy fails, a surgical option is then used especially when a patient reports an excruciating pain or when a deteriorated neurological deficit is observed. During 1980s-1990s, the microsurgical techniques were used to reducethe surgical invasiveness to some extent, however, now new endoscopic techniques are being incorporating to attain a maximum reduction in the invasiveness. ${ }^{12}$ Mixter and Barr (1934) $)^{13}$ were the first who had described the conventional laminectomies and discectomies for the treatment of lumbar herniated disc. These techniques had no excellent outcomes with regard to pain reduction. Therefore, less invasive microsurgical discectomies were developed by using a surgical microscope and monosegmentar. ${ }^{14-16}$ Surgical telescope had been replaced by a microscope in a similar technique as well. ${ }^{17}$ Smith and Foley (1998) ${ }^{18}$ developed an endoscopic technique which was considered a minimal invasive surgical option for lumbar disc herniation (LDH). In this approach, the herniated disc has been used to resect posteriorly with a small incision and a tubular retractor (with a diameter of 16-18 $\mathrm{mm}$ ). The ELD approach was considered to cause less damage of tissue as compared to OLD. A significant reduction in postoperative pain was also noted in ELD option. It was also observed that those patients who were treated with microendoscopic, had returned back to their work much earlier as compared to those patients who were treated with open microdiscectomy. ${ }^{3}$ A latest research of Siepe and Sauer, $(2018)^{12}$ has indicated that a significant reduction in invasiveness is particularly beneficial to the elderly, less mobile patients and obese people. With endoscopic technique, infection and healing problems are minimal, because of smaller skin incision, uniform flow with sterile saline solution as well as a withdrawal of the retractor system. However, considerable surgical skills are required for a lengthy learning curve in endoscopic techniques. ${ }^{12}$ Recent explorations have introduced the concept of minimum invasive surgical techniques and endoscopic lumbar discectomy (ELD) for spine. Full-endoscopic interlaminar technique was proposed by Ruetten et al (2006). ${ }^{19}$ This technique obtains a decompression via. interlaminar window which is used to enter the specific area. This technique is particularly beneficial for L5 - S1 disc herniation. Spine surgeons are now recommending endoscopic lumbar discectomy, because it includes the same path of surgery with familiar anatomy. This technique is found more effective and minimally invasive. But, an accurate understanding of this approach is required to prevent postoperative complications emerge from its steep learning curve. ${ }^{20}$ However, the complication rate is significantly lower as compared to the other microsurgical technique. The use of this ELD approach is increasing because it has an ability to minimize soft-tissue damage and reducenumber of days in hospital stay. Few spine surgeons use an interlaminar endoscopic discectomy technique in L4 L5 herniation as reported earlier. ${ }^{21}$ A percutaneous full-endoscopic discectomy with interlaminar approach was recently used by Nakamura and Yoshihara, (2017). ${ }^{21}$ They evaluated the initial outcomes as well as complications offull-endoscopic discectomy with an interlaminar approach for L4 - L5. 
Based on the calculation of mean operative time, they concluded that this technique can be considered as a standard procedure for any intracanalicular disc herniation. ${ }^{21}$ Sencer et al $(2014)^{22}$ reported that endoscopic lumbar discectomy either with interlaminar or transforaminal surgeries are safer and effective treatments for lumbar disc herniation from the evaluation of the visual analogue score (VAS). But with this new surgical approach, better results would be acquired through sufficient skills and experience of spine surgeons.

\section{MATERIAL AND METHODS}

\section{Study Design}

A prospective randomized control trial from January 2015 to December 2017 was conducted at the Neurosurgery Department of Jinnah Hospital, Lahore. A non-probabilistic, consecutive sampling was done.

\section{Inclusion Criteria}

Male and female patients who were having symptoms of sciatica were selected with ages between $20-60$ years. Those patients included who were taking medicines for last six weeks and experience no improvement in pain.

\section{Exclusion Criteria}

Patients who were clinically diagnosed with cauda equina syndrome were excluded. Patients who were diagnosed with central lumbar disc prolapse on the MRI lumbosacral spine were also excluded.

\section{Data Collection}

A total of 80 patients were admitted from the outpatient department of the hospital. Informed consent were taken from all patients. Patients were grouped either foropen lumbar discectomy - OLD (Group A; $\mathrm{n}=40$ ) or endoscopic lumbar discectomy ELD (Group B; $\mathrm{n}=40$ ), based on randomization through a lottery method.All procedures were done by the same surgeon. All patients were given same analgesics post operatively, i.e. Inj. Ketorolac $30 \mathrm{mg}$ I.V. TDS. The pain was calculated at 24 hours with the help of a visual analog score (VAS) ranging from 0 10. The duration of hospital stay was calculated at the time of discharge. The data was entered on selfdesigned Proforma. The surgical outcome was evaluated in terms of wound site pain and hospital stay. The patients were discharged when either symptoms of sciatica were resolved or when the wound site pain score was found lesser than three and when no discharge was seen from the wound site. Through a designed visual analog score (VAS), the pain was quantified by observing the patient and asking certain questions regarding severity of pain.

\section{Surgical Procedure of Endoscopic Lumbar Discectomy (ELD)-Interlaminar Approach}

The level of the intervertebral disc to be operated was marked with a spinal needle and confirmed by a fluoroscope. A 20-gauge spinal needle was inserted into the Para spinal musculature around one fingerbreadth $(1.5 \mathrm{~cm})$ lateral to the midline side of the patient to be operated at the appropriate disc level. The position of the needle was changed until it positioned directly over the symptomatic disc space. The needle was then removed at the vertical incision of almost $1.5 \mathrm{~cm}(15 \mathrm{~mm})$ that was made just over the disc space. ${ }^{23}$ The incision length made should be about the diameter of the respective tubular retractor. The dilators were inserted by the twisting motion sequentially up to the desired size. A fluoroscope was used to confirm the position of the dilators. The trocar was then passed over the dilators and attached to the self-retaining arm (Figure 1). An endoscopic telescope

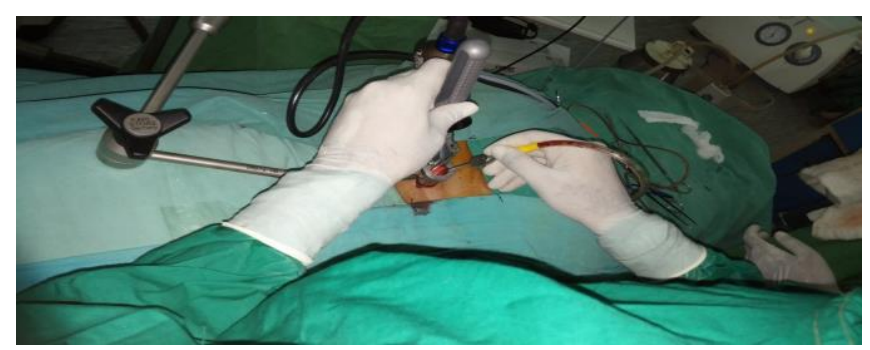

Fig. 1: Dissection Performed in Endoscopic Lumbar via. Tubular Retractor.

was attached to the high definition camera. The soft tissue over the lamina and interlaminar space was removed. Bony landmarks can also be identified by palpation using a long instrument like a suction nozzle tip and lateral fluoroscopy. The lamina was exposed. A hemilaminotomy was then performed and the ligamentum flavum was dissected. The ligament was penetrated with the curette using a twisting motion, peeled back caudally and dorsally, and then resected with a Kerrison punch. The dura and traversing nerve 
root were then identified. The nerve root was retracted medially. An annulotomy was performed using a micro knife (if required), while protecting the nerve root with the suction retractor (Figure 2). The disc material was removed with the help of the pituitary rongeur (Figure 3). Skin was closed using a single stitch (Figure 4). The term percutaneous has been frequently used as a prefix of endoscopic lumbar discectomy, but we do not recommend the use of this term as a prefix, as percutaneous is a procedure in which the portal of entry is created via. needle or

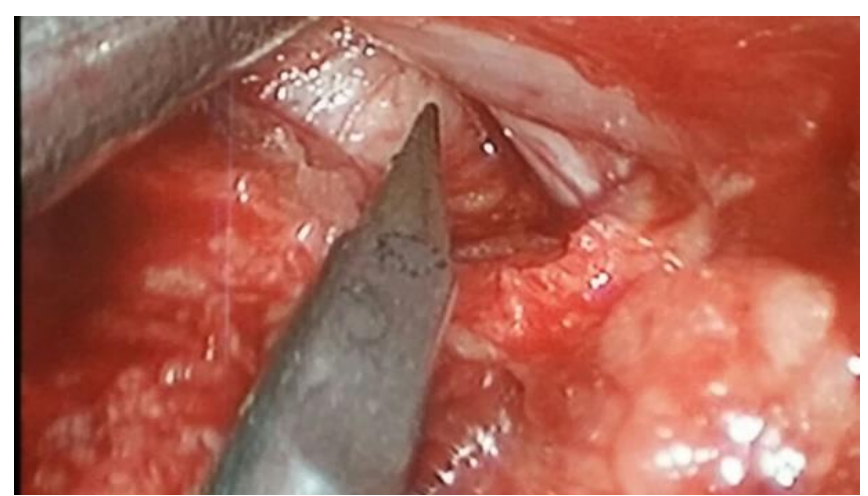

Fig. 2: Sheathed Micro-knife is being used to perform an Annulotomy in Endoscopic Lumbar Discectomy.

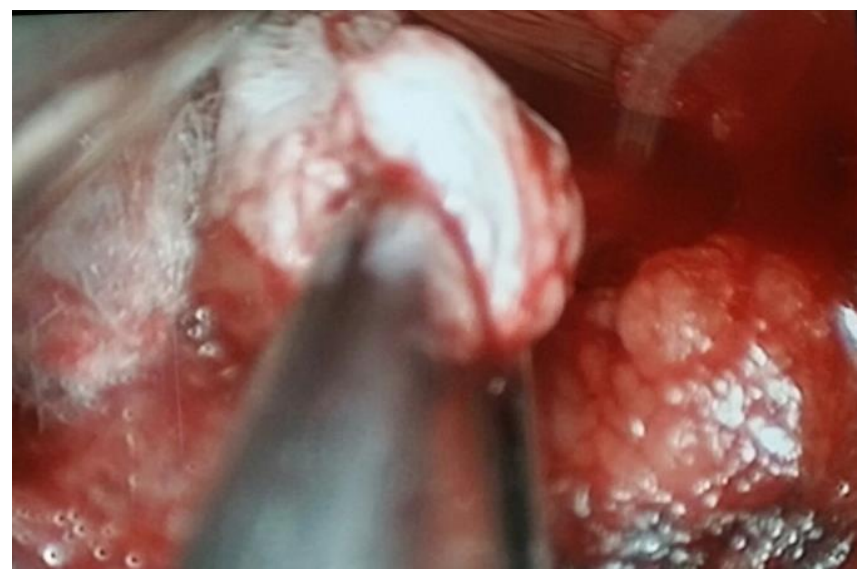

Fig. 3: Disc Material Retrieved Endoscopically. trocar not requiring an incision, whereas in endoscopic lumbar discectomy, we created a small stab incision and subsequently dilating it.

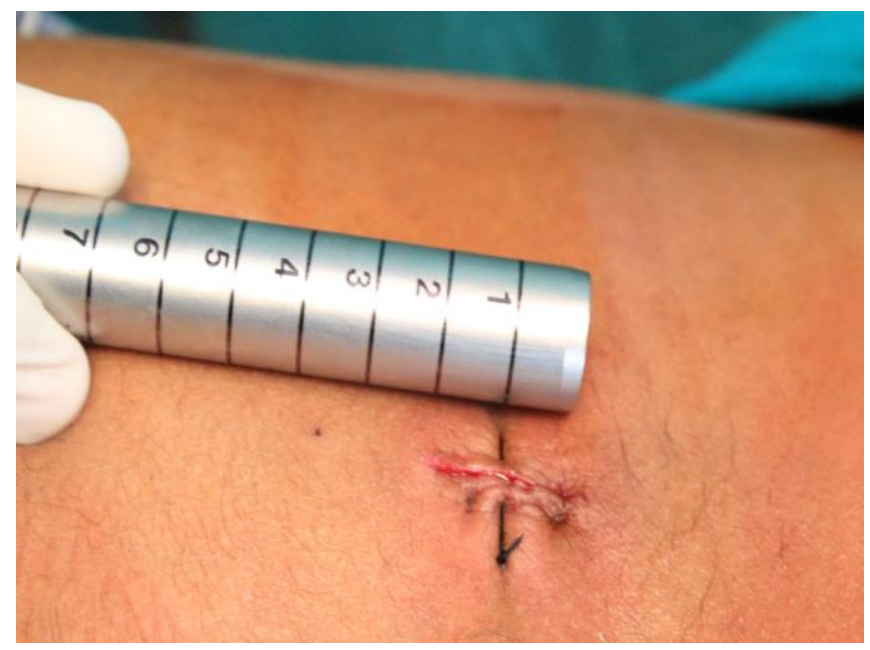

Fig. 4: Surgical Wound of Endoscopic Lumbar Discectomy.

\section{Surgical Procedure of Open Lumbar Discectomy (OLD)}

The patient was placed in a prone position. Fluoroscopy was used for the localization and surface anatomy was utilized. A $3-4 \mathrm{~cm}(30-40 \mathrm{~mm})$ midline incision is made and self-retaining retractors were applied (Figure 5). Subperiosteal dissection of tissue from spinous process and lamina on the

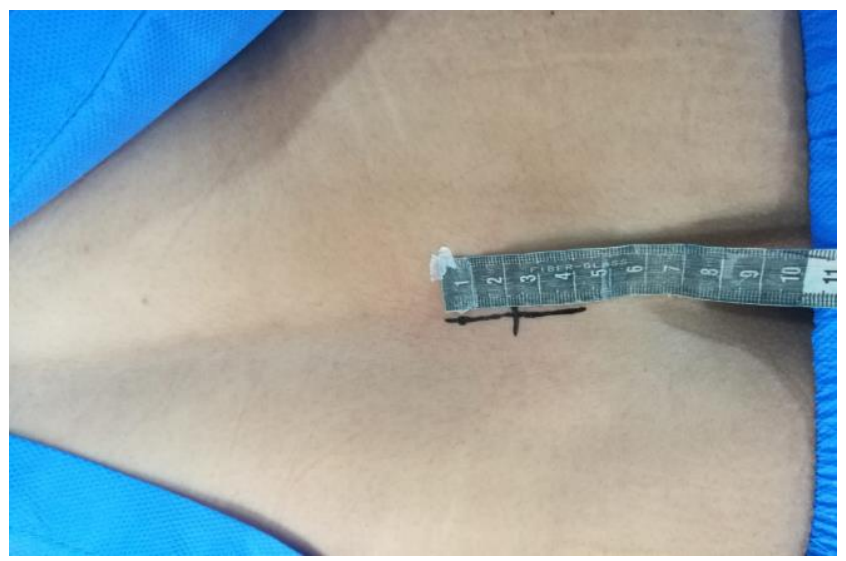

Fig. 5: Incision marking of almost $4 \mathrm{~cm}$.

symptomatic side were performed. Supraspinous and interspinous ligaments should be preserved. A retractor was placed. Partial laminectomies of superior and inferior lamina of identified level. Ligamentous flavum was removed (English correction). The nerve sleeve and dura were gently retracted medially. The posterior longitudinal ligament and annulus fibrosus were incised from medial to lateral. Disc material was 
removed with a pituitary rongeur (Figure 6). The skin was closed with stitches (Figure 7).

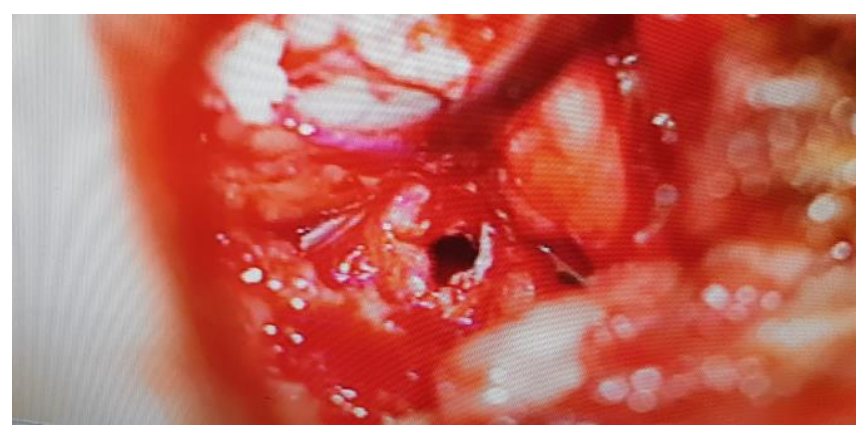

Fig. 6: Disc space after removal of herniated disc material.

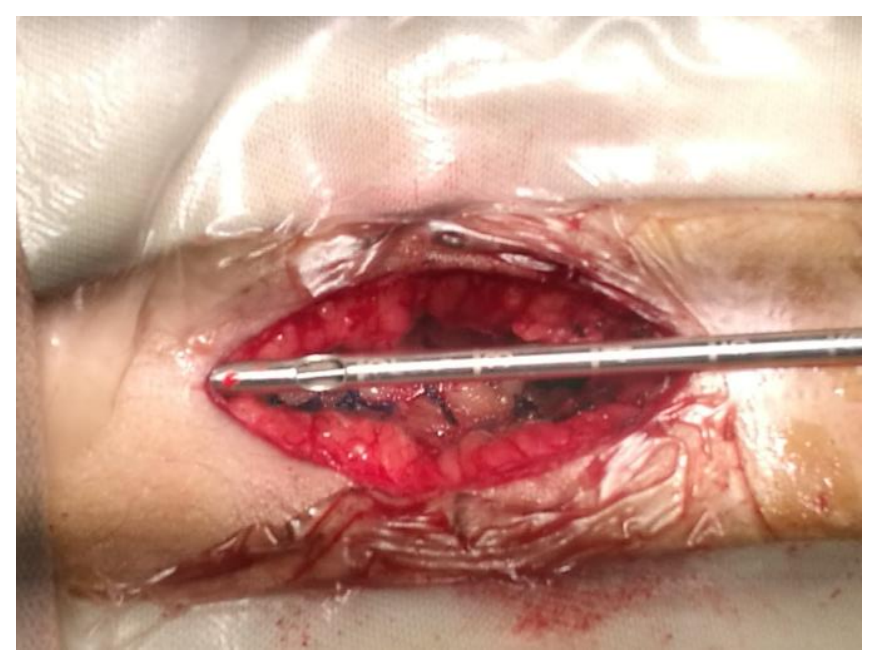

Fig. 7: Surgical Wound of Open Lumbar Discectomy

\section{Medical Management}

A trial of medical management was given to all patients for a maximum six weeks. Almost $80 \%$ of patients responded well to this medication therapy and did not require any surgery. A preoperative medical management included prescribing a combination of an analgesic and a muscle relaxant along with physiotherapy with an avoidance of lifting heavy loads. We prescribed Tablet Piroxicam $20 \mathrm{mg}$ once daily and Tablet Tizanidine $2 \mathrm{mg}$ thrice daily. Those patients were considered for the surgerywho did not report a relive in pain with medicine therapy of six week.

\section{Statistical Analysis}

All data was evaluated on SPSS v.23.0 (IBM Corp., Armonk, New York, US). Mean, minimum, maximum values of following parameters, i.e., age, pre-operative visual analog score (VAS), post-operative visual score (VAS) and hospital stay (in days) were calculated for both groups. A chi-square test was applied to see the association between both groups for each parameter, i.e., age, gender, left/right side disc and vertebral levels. A significance level was considered with pvalue less than 0.050. A chi-square (cross-table) was conducted to see significance or non- significance of association in both groups (A \& B) with respect to preoperative \& post-operative VAS. Chi-square tests were also applied to determine the significance or nonsignificance of association between both groups (A \& B) in the stratification or distribution of post-operative VAS and hospital stay related to mean post-operative VAS in age classification ( $\leq 40$ years of patients \& $>40$ years of patients), in gender classification, in disc side (left/right) classification and in vertebral level classification. Before conducting a comparative analysis between group A (patients treated with OLD) and group B (patients treated with ELD), a Shapiro Wilk test was conducted to confirm normalization or non-normalization in the data of post-operative VAS (visual analog score) and hospital stay (days). A postoperative visual analog score (VAS) was stratified according to age and gender $(n=80)$ and MannWhitney (U) test was applied for the comparison of post-operative VAS between two groups in following: age, gender, disc side and vertebral levels. Similarly, hospital stay data stratification according to age and gender $(\mathrm{n}=80)$ was done and another Mann-Whitney (U) test was applied for a comparison of hospital stay (days) between two groups in following: age, gender, disc side and vertebral levels. A second MannWhitney (U) test was applied for the comparison of post-operative VAS and hospital stay between groups $\mathrm{A}(\mathrm{OLD}) \& \mathrm{~B}(\mathrm{ELD})$.

\section{RESULTS}

There were total 80 patients and among them.

\section{Gender Distribution}

There were 45 (56\%) male patients and 35 (44\%) female patients. Patients were grouped for open lumbar discectomy - OLD (Group A; $\mathrm{n}=40$ ) and endoscopic lumbar discectomy - ELD (Group B; $\mathrm{n}=$ 40). There were $57.5 \%$ male \& $42.5 \%$ female in group A and $55 \%$ male \& $45 \%$ female in group B. 


\section{Age Incidence}

There were $59(74 \%)$ patients who were less than 40 years and $21(26 \%)$ patients who were more than 40 years of age.

\section{Side Involved}

There were $68(85 \%)$ patients with left sided prolapsed paracentral disc and $12(15 \%)$ patients with right sided prolapsed paracentral disc.

\section{Level Involved}

There were 40 (50\%) patients who had L4 - L5 vertebral level, 39 (49\%) had L5-S1 vertebral level, whereas, there was only $1(1 \%)$ patient with vertebral level L3-L4 level.

\section{Mean, Minimum and Maximum Values (Pre \& Postoperative VAS)}

Table 1 describes mean, minimum, maximum values of following parameters, i.e., age, pre-operative visual analog score (VAS), post-operative visual score (VAS) and hospital stay (in days) for both groups. The mean age of patients was 35.5 years in group A and 32.6 years in group B. Mean post-operative VAS was 4.0 in group A and 1.32 in group B. Minimum post-operative VAS was 1 and the maximum was 6 in group A, while, minimum post-operative VAS was 1 and the maximum was 3 in group B. Mean of post-operative VAS was significantly reduced in group B patients who were treated with endoscopic lumber discectomy (ELD). There were 12 patients of group A (treated with OLD) whose post-operative VAS was 5, whereas, there were 30 patients of group B (treated with ELD) whose post-operative VAS was 1. Mean hospital stay was 2.5 days with minimum 1 day and maximum 6 days in group A (treated with OLD) patients, whereas, mean hospital stay was 1.5 days with minimum 1 day and maximum 3 days in group B (treated with ELD) patients. There were 12 patients who stayed two days in hospital after OLD surgery, whereas, there were 23 patients who stayed only one day after ELD surgery.

\section{Stratifications of Visual Analog Score (VAS) and Hospital Stay}

There was a non-significant association (Table 2) between groups $\mathrm{A}$ and $\mathrm{B}$ related to pre-operative and post-operative visual analog scores according to chisquare $(\chi 2=1.667 ;$ p-value $=0.1966)$. The stratifications of post-operative VAS and hospital stay (days) related to age classification, gender classification, left or right prolapsed paracentral disc classification and vertebral levels (L3 - L4, L4 - L5, L5 - S1) in both groups (A and B) was done and no significant association was found between the groups with p-values $=1,1,1,1(\chi 2=0,0,0,0)$ respectively. Similarly, the stratifications of hospital stay (days) related to age classification, gender classification, left or right prolapsed paracentral disc classification and vertebral levels (L3 - L4, L4 - L5, L5 - S1) in both groups (A and B) was done and no significant association was found between the groups with pvalues $=0.465,0.809,0.850,0.465(\chi 2=0.533,0.058$, $0.0356,0.533$ and) respectively.

\section{Shapiro-Wilk Statistics (W) Test Results}

Shapiro-Wilk Statistics (W) test (1) which was conducted to determine normalized/non normalized distribution of post op VAS score and hospital stay (dependents) in gender, age, disc side and vertebral level groups (factors). According to the p-value $<0.050$, all of the data was found non-normalized. Therefore, for comparisons a Mann-Whitney (U) test

Table 1: Mean, min, max values of relevant parameters with respect to patients groups: OLD \& ELD*.

\begin{tabular}{|l|c|c|c|c|c|c|}
\hline \multirow{2}{*}{ Parameter } & \multicolumn{3}{|c|}{$\begin{array}{c}\text { Open Lumbar Discectomy (OLD) } \\
\text { Group A (n= 40) }\end{array}$} & \multicolumn{2}{c|}{$\begin{array}{c}\text { Endoscopic Lumbar Discectomy (ELD) } \\
\text { Group B (n= 40) }\end{array}$} \\
\cline { 2 - 7 } & Mean \pm S.D. & Min. & Max. & Mean \pm S.D. & Min. & Max. \\
\hline Age (Years) & $35.55 \pm 8.726$ & 20 & 50 & $32.675 \pm 8.300$ & 20 & 49 \\
\hline Pre-Operative VAS** & $5.05 \pm 1.518$ & 2 & 8 & $5.825 \pm 1.852$ & 2 & 9 \\
\hline Post-Operative VAS & $4.025 \pm 1.671$ & 1 & 8 & $1.325 \pm 0.615$ & 1 & 3 \\
\hline Hospital Stay (days) & $2.5 \pm 1.240$ & 1 & 6 & $1.525 \pm 0.678$ & 1 & 3 \\
\hline
\end{tabular}

*OLD: Open Lumbar Discectomy, ELD: Endoscopic Lumbar Discectomy; **VAS: Visual analog score 
Postoperative Wound Pain and Hospital Stay in Patients of Open Lumbar Discectomy (OLD) Versus Endoscopic

Table 2: Distribution of mean pre-operative and post-operative VAS in groups: OLD \& ELD.

\begin{tabular}{|c|c|c|c|c|}
\hline \multirow[b]{2}{*}{ VAS } & \multicolumn{2}{|c|}{ Surgery Options } & \multirow{2}{*}{$\begin{array}{l}\text { Chi Square } \\
\quad\left(\chi^{2}\right)\end{array}$} & \multirow[b]{2}{*}{$p$ value } \\
\hline & $\begin{array}{c}\text { Open Lumbar Discectomy } \\
(\text { OLD })(n=40)\end{array}$ & $\begin{array}{c}\text { Endoscopic Lumbar Discectomy } \\
(\text { ELD })(n=40)\end{array}$ & & \\
\hline Pre-operative VAS & 5.05 & 5082 & \multirow{3}{*}{1.667} & \multirow{3}{*}{0.1966} \\
\hline Post-operative VAS & 4.025 & 1.325 & & \\
\hline Total & 9 & 7 & & \\
\hline
\end{tabular}

was applied. A second ShapiroWilk Statistics (W) test determined a non-normalized distribution of post-operative visual analog scores and hospital stay in Groups A \& B (i.e., OLD \& ELD). Therefore, for further comparison, a MannWhitney (U) test was applied.

\section{Mann-Whitney (U) Test Results}

According to Mann-Whitney (U) test, a significant difference ( $\mathrm{p}$ value 0.037 ) was only reported between vertebral levels (i.e., L4 - L5 \& L5 - S1) in the comparison of mean post-operative VAS.A second Mann-Whitney U test indicated (Table 3) that postoperative VAS in group A was statistically significantly higher ( $\mathrm{p}$ value $<0.000$ ) than the group B. This Mann-Whitney $U$ test also indicated that hospital stay (days) in group A was also statistically significantly higher $(\mathrm{p}$ value $<0.000)$ than the group B.

\section{DISCUSSION}

We compared the mean (pain) visual analog scores (VAS) and hospital stay (in days) after endoscopic lumbar discectomy (ELD) and open lumbar discectomy (OLD). Recent research has recommended an interlaminar based endoscopic lumbar discectomy for the treatment of lumbar disc herniation (LDH). ${ }^{20,21}$ In current research, the mean post-operative VAS was 4.0 in group A (treated with OLD) and 1.32 in group B (treated with ELD). As the minimum post-operative VAS was 1 and the maximum was 6 in group A (OLD), while, minimum post-operative VAS was 1 and the maximum was 3 in group B (ELD). Therefore, mean post-operative VAS was significantly reduced in group B patients, who were treated with endoscopic lumbar discectomy (ELD). It is noteworthy that there were 12 patients of group A (OLD) whose postoperative VAS was 5, whereas, there were 30 patients found in group B (ELD) whose post-operative VAS was 1 . The mean hospital stay was 2.5 days in group A patients, whereas, mean hospital stay was 1.5 days in group B patients. It was worth to note that there were 12 patients who stayed two days in hospital after OLD surgery, whereas, there were 23 patients who stayed only one day after ELD surgery. Asignificant difference ( $p$ value 0.037) was found in the comparison of mean post-operative VAS between two groups in vertebral levels (i.e., L4 - L5 \& L5 - S1). Mann-Whitney $U$ test indicated that post-operative VAS in group A was statistically significantly higher ( $\mathrm{p}$ value $=0.000)$ than the group B. Mann-Whitney $\mathrm{U}$ test also indicated that hospital stay (days) in group A was statistically significantly higher $(\mathrm{p}$ value $=0.000)$ than the group B.

Our results regarding endoscopic lumbar discectomy (ELD) approach are comparable to that of other published studies.Many reports have proved the efficacy of ELD as compared to the OLD. ${ }^{23,25-26}$ The mean postoperative was 1.32 in patients who were treated with endoscopic lumbar discectomy and it was 4 in patients treated with open lumbar discectomy. This result was statistically significant between both groups $(p<0.0001)$. Haung et al $(2013)^{27}$ showed that the VAS in patients of endoscopic lumbar discectomy was 1.4. Teli et al $(2016)^{28}$ also showed that the average post-operative pain was 3 on VAS scale in endoscopic lumbar discectomy. Hsu et al (2012) $)^{29}$ observed that the patients who underwent endoscopic 
lumbar discectomy had a post-operative VAS of 1.6. Similarly, we observed a reduction in hospital stay in patients who were treated with endoscopic lumbar discectomy (mean 1.5 days) as compared to patients who were treated with open lumbar discectomy (mean 2.5 days). This result was also statistically significant between both groups $(p<0.0001)$. Lee et al $(2009)^{30}$ reported that the average hospital stay was around 1 day in endoscopic lumbar discectomy. Haung et al $(2013)^{27}$ mentioned that the postoperative hospital stay was less than 4 days in an endoscopic lumbar discectomy group. While, according to Teli et al $(2016)^{28}$ the average hospital stay was 54 hours in the same group. The outcomes of ELD were found better than that of the OLD group in terms of hospital stay and post-operative wound site pain. A retrospective study conducted by Xie et al $(2017)^{20}$ to evaluate the complications of the new technique. Xie et al $(2017)^{20}$ treated around 200 cases of L4 - L5 herniation and observed a good outcome. They mentioned that this approach has not many complications if properly handled. They reported less complicationsthat were due to the observed nerve root injury, paresthesia and incomplete decompression. It was recommended that with effective measures, precise surgical procedure, targeted perioperative management as well as expertise and skills in such surgery can further reduce complication rates. ${ }^{20}$ Choi et al $(2011)^{31}$ reported complication rate around $18 \%$ by an endoscopic approach. Phan et al $(2017)^{32}$ conducted a metaanalysis to evaluate the effectiveness of full and micro endoscopic discectomies with open discectomy in treating lumbar disc herniation. Although, Phan et al $(2017)^{32}$ found similar results in both approaches related to visual analogue score (VAS leg) and Oswestry disability index (ODI), but an improved outcome in terms of patient satisfaction, less operative time, less blood loss and hospital stay were reported with an endoscopic approach. It was concluded that although, both of these approaches were safe and effective, but still further research is required for an adequate validation. ${ }^{32}$ Choi et al $(2013)^{33}$ reported that mean VAS (back and leg) were significantly improved in percutaneous endoscopic lumbar discectomy with both approaches, i.e., transforaminal vs. interlaminar. The significance of endoscopic spine surgical approach has also been tested in serious conditions such as large lumbar herniation where conventional surgery does not workin herniated disc evaluations. ${ }^{34}$ Choi et al (2016) ${ }^{34}$ compared the clinical outcomes of endoscopic lumbar discectomy (ELD) with an open lumbar technique (OLD). It was reported that ELD was more effective for large lumbar herniation as compared to OLD in terms of an earlier recovery, reduction in pain and disc height preservations. A study compared the outcomes of percutaneous endoscopic lumbar discectomy with open lumbar microdiscectomy in patients with recurrent disc herniation. A significant reduction ( $p$ value $<0.001$ ) in operation time and hospital stay was found in ELD group. The less rate of complication, improvement in backaches and adequate disc height preservation were reported in ELD group as well. ${ }^{30}$ A retrospective study also reported that ELD approach in recurrent disc herniation was effective. ${ }^{35}$ Another study reported through the evaluation of VAS and ODI, that full endoscopic surgical option has a safer implementation and a good alternative to open microsurgery in patients with lumbar disc herniation. Although, they found same clinical outcomes with both approaches, but they achieved advantages with endoscopic option in terms of reduced traumatization andbackaches. ${ }^{36}$ It was mentioned by Ruetten et al $(2008)^{36}$ that with proper procedures and surgical instruments, the endoscopic lumbar discectomy either with interlaminar or transforaminal options, the inside/outsidespinal canal in LDHs (lumbar disc herniations) can sufficiently be removed. Sencor et al $(2014)^{22}$ mentioned complications in a few patient who were treated with full endoscopic lumbar discectomy as dysesthesia $(2.4 \%)$, deteriorated neurological status $(3 \%)$ and dural tears $(3.7 \%)$. Dysesthesia was resolved in time, and deteriorated neurological condition was restored without any intervention..$^{22}$ Jhala and Mistry $(2010)^{26}$ and Ranjan et al (2006) ${ }^{37}$ reported hospital stay of 1 2 days with endoscopic lumbar discectomy in around 100 cases. A study by Schizas et al $(2005)^{38}$ compared the outcomes of microendoscopic discectomies with standard microsurgical discectomies and noted that the former were at least equally effective for the treatment of large contained disc herniation. Less tissue invasions, lesser intake of analgesics and an early return to activities have been associated with ELDs. ${ }^{26}$

Katayama et al $(2006)^{39}$ compared the results of an open lumbar discectomy versus endoscopic lumbar discectomy and found no difference in the surgical outcomes with both techniques. An endoscopic "lumbar discectomy provide better lighting, magnification and reducethe incision length and tissue invasion". ${ }^{39}$ It was reported that with endoscopic lumbar discectomy, the patients returned to the functional state much earlier even with the lesser 
intake of postoperative narcotic analgesics. Therefore, if both procedures have the even same outcomes, than a less invasive procedure with a lesser use of postoperative analgesics and an early return to life or work should be the procedure of choice. Endoscopic Lumbar Discectomy (ELD) was introduced to combine standard lumbar microsurgical techniques with an endoscope and therefore, spine surgeons can handle factors related to free-fragment disc pathology and lateral recess stenosis successfully. ${ }^{40}$ The endoscopic approach includes smaller incisions and less tissue trauma as compared to standard open discectomy. Long term potential should also be evaluated to maintain standard endoscopic discectomy. ${ }^{26}$ In our setup, the patients were operated with only $15 \mathrm{~mm}$ (average) skin incision and postoperative MRIs showed lesser signal changes in the paraspinal muscles. Endoscopic Lumbar discectomy will rise all over the world due to its minimal invasive approach and improved outcomes, but its long term outcomes are yet to be established. The safe removal of the prolapsed disc and improved VAS have convinced neurosurgeons to adopt an ELD procedure. But, it demands an endoscopic procedural skills asit has a steeper and a lengthy learning curve. We performed ELD in our institution and our results have shown that ELD is superior to open discectomy in terms of reduced VAS and hospital stay.

\section{CONCLUSION \& RECOMMENDATION}

Open lumbar discectomy had been the procedure of choice. As surgical specialties are moving to minimal invasive techniques, the neurosurgeons have moved from open discectomy to micro discectomy and ending up to endoscopic discectomy. Although, the results of microdiscectomy are favorable but endoscopic discectomy also proving its place and the patients are getting benefits regarding less wound site pain, less hospital stay and smaller incisions. Endoscopic Lumbar discectomy is a minimally invasive procedure for discectomy in early encouraging results. It has a steep learning curve initially, but once the expertise is maintained over this technique, the results are more acceptable in terms of safety and effectiveness as compared to open lumbar discectomy related to postoperative wound site pain and hospital stay.

More research is required regarding evaluating maximum benefits, well- designed standard procedures, skills and reducing complications with endoscopic lumbar discectomies.

\section{REFERENCES}

1. Bakhsh A. Long-term outcome of lumbar disc surgery: an experience from Pakistan. Journal of Neurosurgery: Spine, 2010; 12 (6): 666-70.

2. Peul WC, Van Houwelingen HC, van den Hout WB, et al. Surgery versus prolonged conservative treatment for sciatica. New Engl J Med. 2007; 356 (22) :2245-56.

3. Righesso O, Falavigna A, Avanzi O. Comparison of open discectomy with microendoscopic discectomy in lumbar disc herniations: results of a randomized controlled trial. Neurosurg. 2007; 61 (3): 545-9.

4. Martin BI, Deyo RA, Mirza SK, et al. Expenditures and health status among adults with back and neck problems. JAMA. 2008; 299 (6): 656-64.

5. Wahlström J, Burström L, Nilsson T, et al. Risk factors for hospitalization due to lumbar disc disease. Spine, 2012; 37 (15): 1334-9.

6. Akbar A, Mahar A. Lumbar disc prolapse: Management and outcome analysis of 96 surgically treated patients. J Pak Med Association, 2002; 52 (2): 62-5.

7. Friberg S, Hirsch C. Anatomical and clinical studies on lumbar disc degeneration. Acta Orthop Scandinavica. 1949; 19 (2): 222-42.

8. Schultz A, Andersson G, Ortengren R, et al. A. Loads on the lumbar spine. Validation of a biomechanical analysis by measurements of intradiscal pressures and myoelectric signals. J bone joint Surg Am. 1982; 64 (5): 713-20.

9. Deyo RA, Rainville J, Kent DL. What can the history and physical examination tell us about low back pain? JAMA. 1992; 268 (6): 760-5.

10. Taher F, Essig D, Lebl DR, et al. Lumbar degenerative disc disease: current and future concepts of diagnosis and management. Ad Orthop. 2012; 2012.

11. Fager CA. Observations on spontaneous recovery from intervertebral disc herniation. Surgical neurology, 1994; 42 (4): 282-6.

12. Siepe CJ, Sauer D. Technique of full-endoscopic lumbar discectomy via an interlaminar approach. Eur Spine J. 2018; 27 (4): 566-7.

13. Mixter WJ, Barr JS. Rupture of the intervertebral disc with involvement of the spinal canal. J Neurosurg. 1964; 21 (1): 74-81.

14. Caspar W. A new surgical procedure for lumbar disc herniation causing less tissue damage through a microsurgical approach. Lumbar disc adult hydrocephalus, 1977; 74-80.

15. Yasargil M. Microsurgical operation of herniated lumbar disc. Lumbar Disc Adult Hydrocephalus: Springer, 1977: p. 81-.

16. Williams RW. Lumbar disc disease: Microdiscectomy. Neurosurg Clin. 1993; 4 (1): 101-8.

17. Simeone F. The neurosurgical approach to lumbar disc disease. The Orthopedic Clinics of North America, 1971; 2 (2): 499.

18. Smith MM, Foley KT. Microendoscopic discectomy 
(MED): the first 100 cases. Neurosurg. 1998; 43 (3): 702.

19. Ruetten S, Komp M, Godolias G. A new fullendoscopic technique for the interlaminar operation of lumbar disc herniations using 6-mm endoscopes: prospective 2-year results of 331 patients. MinMinimally Invasive Neurosurg. 2006; 49 (02): 80-7.

20. Xie T-H, Zeng J-C, Li Z-H, et al. Complications of Lumbar Disc Herniation Following Full-endoscopic Interlaminar Lumbar Discectomy: A Large, SingleCenter, Retrospective Study. Pain Physician, 2017; 20 (3): E379-E87.

21. Nakamura J, Yoshihara K. Initial clinical outcomes of percutaneous full-endoscopic lumbar discectomy using an interlaminar approach at the L4-L5. Pain Physician, 2017; 20 (4): E507-E12.

22. Sencer A, Yorukoglu AG, Akcakaya MO, et al. Fully endoscopic interlaminar and transforaminal lumbar discectomy: short-term clinical results of 163 surgically treated patients. World Neurosurg. 2014; 82 (5): 88490.

23. Perez-Cruet MJ, Foley KT, et al. Microendoscopic lumbar discectomy. Neurosurgery, 2002; 51 (suppl_2): S2-129-S2-36.

24. Ali, B. Handbook of Spine Surgery, 49 Open and MIS Lumbar Microdiscectomy DOI: 10.1055/b-0034-82989, Thieme Verlabdsgruppe, Stuttgart, New York, Delhi, Rio, 2012.

25. Junaid M, Rashid MU, Afsheen A, et al. A. Analysis of 1058 Lumbar Prolapsed Intervertebral Disc Cases in Two Tertiary care Hospitals of Pakistan. J Ayub Med Col Abbottabad, 2016; 28 (2): 281-4.

26. Jhala A, Mistry M. Endoscopic lumbar discectomy: Experience of first 100 cases. In J Orthop. 2010; 44 (2): 184.

27. Huang C-J, Tang H-W, Liang D-B, et al. Treatment of the recurrent lumbar disc herniation: a comparison between endoscopic surgery and open surgery. Zhongguogushang. China J Orthop Traumatol. 2013; 26 (10) :810-4.

28. Teli M, Lovi A, Brayda-Bruno M, et al. Higher risk of dural tears and recurrent herniation with lumbar microendoscopic discectomy. Eur Spine J. 2010; 19 (3): 44350.

29. Hsu H-T, Chang S-J, Yang SS, et al. Learning curve of full-endoscopic lumbar discectomy. Eur Spine J. 2013; 22 (4): 727-33.
30. Lee DY, Shim CS, Ahn Y, et al. Comparison of percutaneous endoscopic lumbar discectomy and open lumbar microdiscectomy for recurrent disc herniation. $\mathbf{J}$ Korean Neurosurg Society, 2009; 46 (6): 515.

31. Choi G, Kang H-Y, Modi HN, et al. Risk of developing seizure after percutaneous endoscopic lumbar discectomy. Clinical Spine Surg. 2011; 24 (2): 83-92.

32. Phan K, Xu J, Schultz K, et al. Full-endoscopic versus micro-endoscopic and open discectomy: A systematic review and meta-analysis of outcomes and complications. Clin Neurol Neurosurg. 2017; 154: 1-12.

33. Choi K-C, Kim J-S, Ryu K-S, et al. Percutaneous endoscopic lumbar discectomy for L5-S1 disc herniation: transforaminal versus interlaminar approach. Pain Physician, 2013; 16: 547-556.

34. Choi K-C, Park C-K. Percutaneous Endoscopic Lumbar Discectomy for L5-S1 Disc Herniation: Consideration of the Relation between the Iliac Crest and L5-S1 Disc. Pain Physician, 2016; 19 (2): E301-8.

35. Ahn Y, Lee S-H, Park W-M, et al. Percutaneous endoscopic lumbar discectomy for recurrent disc herniation: surgical technique, outcome, and prognostic factors of 43 consecutive cases. Spine, 2004; 29 (16): E326-E32.

36. Ruetten S, Komp M, Godolias G. An extreme lateral access for the surgery of lumbar disc herniations inside the spinal canal using the full-endoscopic uniportal transforaminal approach-technique and prospective results of 463 patients. Spine, 2005; 30 (22): 2570-8.

37. Ranjan A, Lath R. Microendoscopic discectomy for prolapsed lumbar intervertebral disc. Neurology India, 2006; 54 (2): 190.

38. Schizas C, Tsiridis E, Saksena J. Microendoscopic discectomy compared with standard microsurgical discectomy for treatment of uncontained or large contained disc herniations. Oper Neurosurg. 2005; 57 (suppl_4): ONS-357-ONS-60.

39. Katayama Y, Matsuyama Y, Yoshihara H, et al. Comparison of surgical outcomes between macro discectomy and micro discectomy for lumbar disc herniation: a prospective randomized study with surgery performed by the same spine surgeon. Clin Spine Surg. 2006; 19 (5): 344-7.

40. Foley KT, Smith MM, Rampersaud YR. Microendoscopic approach to far-lateral lumbar disc herniation. Neurosurg Focus, 1999; 7 (5): E7. 


\section{sAdditional Information}

Disclosures: Authors report no conflict of interest.

Ethical Review Board Approval: The study was conformed to the ethicalreview board requirements.

Human Subjects: Consent was obtained by all patients/participants in this study.

Conflicts of Interest:

In compliance with the ICMJE uniform disclosure form, all authors declare the following:

Financial Relationships: All authors have declared that they have no financial relationships at present or within the previous three years with any organizations that might have an interest in the submitted work.

Other Relationships: All authors have declared that there are no other relationships or activities that could appear to have influenced the submitted work.

Address for Correspondence:

Dr. Syed Shahzad Hussain

Department of Neurosurgery

Jinnah Hospital, Lahore - Pakistan

Email: drshahidsaman@gmail.com

\begin{tabular}{|c|c|c|c|}
\hline \multicolumn{4}{|c|}{ AUTHORSHIP AND CONTRIBUTION DECLARATION } \\
\hline Sr.\# & Author's Full Name & Intellectual/Contribution to Paper in Terms of: & \multirow{7}{*}{$\begin{array}{l}\text { Signature by the } \\
\text { author(s) }\end{array}$} \\
\hline 1. & Syed Shahzad Hussain & \multirow{6}{*}{$\begin{array}{l}\text { 1. Proposed topics and Basic Study Design, methodology. } \\
\text { 2. Data collection and calculations } \\
\text { 3. Analysis of data. } \\
\text { 4. Literature review } \\
\text { 5. Paper writing and Analysis of data } \\
\text { 6. Study Design and surgeries }\end{array}$} & \\
\hline 2. & Usman Ahmad Kamboh & & \\
\hline 3. & Asif Raza & & \\
\hline 4. & Adil Ameen & & \\
\hline 5. & Saman Shahid & & \\
\hline 6. & Naveed Ashraf & & \\
\hline
\end{tabular}

Date of Submission: 21-01-2020

Date of Revision: 25-03-2020

Date of Online Publishing: 31-03-2020

Date of Print: 31-03-2020 